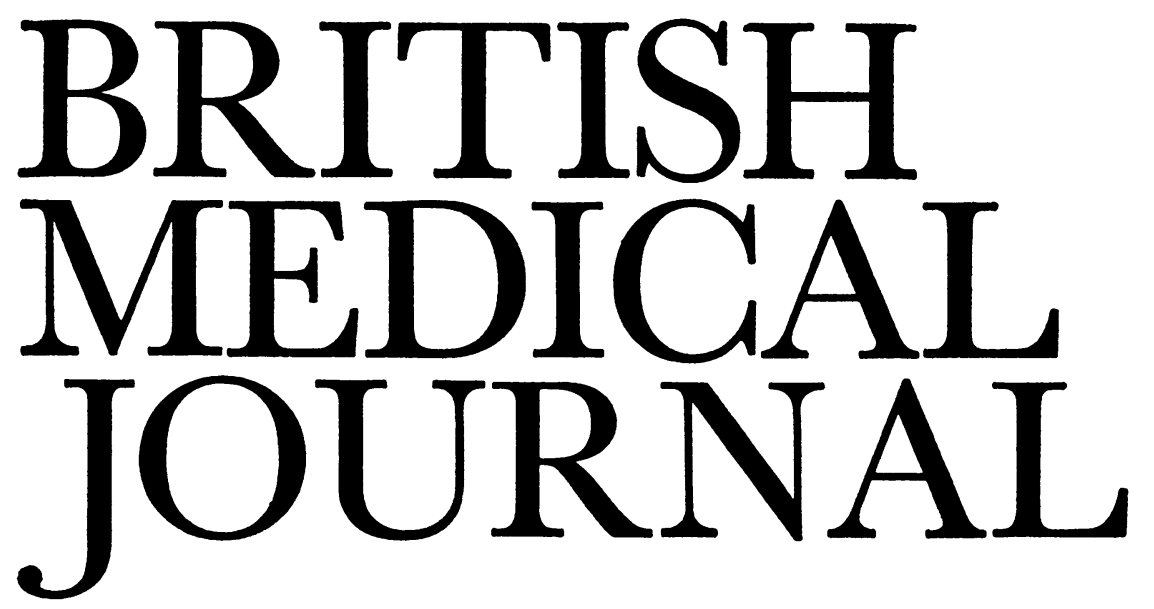

LONDON SATURDAY 8 JULY 1972

\title{
Pulmonary Oedema of Mountains
}

Cheap air travel now enables people to visit distant mountains that were formerly accessible only after a slow approach allowing some acclimatization to the altitude. The consequence is that a serious and sometimes fatal disease is increasingly prevalent, though still uncommon, among travellers in high mountains. Cases are being seen among tourists, scientists, sportsmen, soldiers, and other visitors to them, for it is possible within a day or so of leaving Europe to be at an altitude of $12,000 \mathrm{ft}(3,600 \mathrm{~m})$ or more. In Kenya, for instance, some ten or more cases are being seen every year, among them a few fatalities.

In some respects resembling an acute pneumonia, the condition now known as high-altitude pulmonary oedema has long been known as a hazard to mountain climbers. A decade ago it became clear that the disease does not respond to antibiotics and that the victims of it have neither a history nor, on recovery, residual signs of cardiovascular disease. ${ }^{1-6}$ The main knowledge of it in recent times has been gained by medical officers in the Indian Army, who have seen many cases among troops transported from the lowlands to Himalayan stations. ${ }^{78}$

The first symptoms of the illness ${ }^{8}$ include headache, nausea, loss of appetite, breathlessness, insomnia, muscular weakness, giddiness, and gastrointestinal upset. They generally appear on about the third day at high altitude and at first are indistinguishable from those of ordinary mountain sickness, a relatively common, harmless, and transient condition. But as the true pulmonary oedema develops, often with alarming rapidity, the patient develops a cough and may experience irregular or Cheyne-Stokes breathing, oligurea, mental confusion and hallucinations, stupor, seizures, and coma. Pulmonary oedema may sometimes develop without any mountain sickness as prelude. Surprisingly, the people most at risk appear to be muscular males in their teens or early 20s who are in good physical condition. Sometimes the most active member of a party has been the one affected. Women have not so far been recorded as victims of the disease. At necropsy the main findings have been cerebral and pulmonary oedema. ${ }^{8}$

The condition is unknown below $9,000 \mathrm{ft}(2,700 \mathrm{~m})$ and rare below $12,000 \mathrm{ft}(3,600 \mathrm{~m})$. The peak risk seems to be between 12 and 72 hours after going above $9,000 \mathrm{ft}$ $(2,700 \mathrm{~m})$. Exposure to cold is a feature in some cases. Fatalities have occurred after swimming in the icy water of high-altitude tarns. In some cases the man seems to have been suffering from an infection of the upper respiratory tract before starting to climb.

The pathophysiological mechanism of the condition is unknown, but as with ordinary pulmonary oedema there is probably a shift of circulating fluid from the peripheral systemic circuit to the central pulmonary circuit. It may be significant that $9,000 \mathrm{ft}(2,700 \mathrm{~m})$ is the altitude at which hypoxia begins to dominate the control of ventilation and at which arterial $\mathrm{PCO}_{2}$ begins to fall. ${ }^{9}$ A low $\mathrm{PCO}_{2}$ causes constriction of peripheral veins ${ }^{1011}$ and tends to dilate pulmonary arterioles. ${ }^{12}$ Both these mechanisms would therefore lead to a shift of fluid to the pulmonary capillaries. This might be aggravated by peripheral venoconstriction occurring as a result of exposure to cold. Another minor factor might be a lowered pressure of the pulmonary interstitial fluid as a consequence of reduced atmospheric pressure. However, it must be admitted that these suggestions are at best speculative and that the true mechanism is unknown.

Despite our ignorance of the exact cause of the condition the epidemiology of it gives some clues to how it may be prevented. A major problem is that most climbers without experience of high altitudes do not believe that apparently healthy people can die so easily. Consequently, posters or pamphlets giving guidance in simple language should be brought to their notice at hotels and camps where they may be staying. They should emphasize the dangers of ascending too rapidly, of over-exertion, of exposure to cold and swimming in icy water, and of starting up the mountain while suffering from a cough or cold.

For the treatment of the condition it is generally agreed that the patient should be carried to lower altitudes as soon as possible. Stretchers and oxygen should be available at strategic points at high altitude and should be used when there is any suspicion of pulmonary oedema. The beneficial effect of oxygen is not clearly understood. It may slow the ventilation and allow the $\mathrm{PCO}_{2}$ to rise to normal levels, and in serious cases with considerable impairment of pulmonary gas exchange it should increase the oxygenation of arterial blood. Next to oxygen the best treatment depends on whether or not medically trained people are available. Experience has shown that climbers without medical training are extremely reluctant to administer drugs by any route other than by mouth and that tired climbers, partially confused because of hypoxia, may be unable to follow the 
simplest instructions. The diuretic frusemide, two $40-\mathrm{mg}$ tablets four-hourly until medical help is available, is recommended on the general grounds that a reduction in the volume of body fluid is likely to be desirable, though it is admitted that there is no direct evidence of this in the highaltitude form of pulmonary oedema. Frusemide also offers some psychological advantage, for the diuresis reassures the patient that a potent drug with an obvious effect is being given to help him.

If qualified medical help is available, it seems generally agreed that morphine as well as frusemide should be given and that it sometimes produces a dramatic improvement, ${ }^{8}$ perhaps partly because of its sedative effect and partly because of its peripheral venodilator action. ${ }^{13}$ But agreement is lacking on the use of cardiac glycosides, some authorities advocating them and some denying their value. One form of treatment which does seem to be of real help in severe cases is positive-pressure artificial ventilation, which among other things will raise the pulmonary interstitial fluid pressure.

At present the causes and mechanism of high-altitude pulmonary oedema are far from being understood, and because of the environmental conditions in which it occurs controlled trials of different forms of treatment present obvious problems. But simple education of people visiting high mountains will help to prevent it, and the provision of emergency stretchers, oxygen, and frusemide (with clear instructions on their use) in huts at high altitude will allow effectual first aid to be carried out.

1 Alzamora-Castro, V., Garrido-Lecca, G., and Battilana, G., American Fournal of Cardiology, 1962, 7, 769.

2 Fred, H. L., Schmidt, A. M., Bates, T., and Hecht, H. H., Circulation, $1962,25,929$.

3 Houston, C. S., New England Fournal of Medicine, 1960, 263, 478.

4 Hultgren, H. N., Spickard, W., Heliriegel, K., and Houston, C. S., Medicine, 1961, 40, 289.

5 Hultgren, H. N., Spickard, W., and Lopez, C., British Heart fournal,

1962, 24, 95.

Fenn and H. Rahn. Washington, American Physiological Society, 1965.

7 Singh, I., Kapila, C. C., Khanna, P. K., Nanda, R. B., and Rao, B. D. P., Lancet, 1965, 1, 229.

B Singh, I., et al., New England fournal of Medicine, 1969, 280, 175.

Boothby, W. M., Lovelace, W. R., Benson, O. O., and Strehler, A. F., in Handbook of Respiratory Physiology, ed. W. M. Boothby. Texas, USAF School of Aviation Medicine, 1954.

10 Wood, J. E., and Roy, S. B., American fournal of Medical Science, 1970 259, 56.

1 Weil, J. V., Byrne-Quinn, E., Battock, D. J., Grover, R. F., and Chidsey, C. A., Clinical Science, 1971, 40, 235.

12 Cross, K. W., in Handbook of Physiology, Section 3, vol. 2, ed. W. O. Fenn and H. Rahn. Washington, American Physiological Society, 1965.

13 Henney, R. P., Vasko, J. S., Brawley, R. K., Oldham, H. N., and Morrow, A. G., American Heart fournal, 1966, 72, 242.

\section{Puzzling Cases of Secondary Syphilis}

Before the days of specialization the great physicians recognized syphilis as a disease with such protean manifestations that its diagnosis of ten presented great difficulties. This was in particular true of early acquired syphilis in the secondary stage of the disease, when over 80 other diseases had to be considered in the differential diagnosis from its many and various clinical forms. Nowadays it is true that only about $2 \%$ out of all cases seen in the special clinics are due to syphilis in all stages, but even so over 1,000 new cases of early infectious syphilis were reported in 1970. It is probable that a large number of other cases remained undiagnosed or were misdiagnosed in general and specialist practice in the same year.

Britain is fortunate in having a highly organized venereal disease service, with consultants specializing in the subject and contributing to the teaching of undergraduate and postgraduate students. They are able to emphasize to doctors in training the importance of appreciating that patients with early syphilis in the secondary stage rarely present directly to the special clinics. The main symptoms of lassitude, anorexia, headache, sore throat, hoarseness, and arthralgia are common to many other organic or functional diseases. A general practitioner may note that he is dealing with an inflammatory condition by finding pyrexia and anaemia associated with a raised erythrocyte sedimentation rate, but the common signs of rashes, mucosal and perianal lesions, and general adenopathy may persuade him to refer the patient to a dermatologist, an otolaryngologist, a proctologist, or a general physician. There are also a small percentage of cases with rarer secondary lesions of the meninges, the uveal tract of the eye, the viscera, and the bones, which may bring the patient to a neurologist, an ophthalmologist, a gastroenterologist, or an orthopaedic surgeon.

A recent paper by J. D. J. Parker ${ }^{1}$ is of particular interest in this respect, as he was able to report one case of each of these four rare manifestations of the secondary stage seen in a special clinic. Case 1 was of a 43 -year-old homosexual male admitted deeply jaundiced. Liver biopsy showed slight cellular infiltration with round cells, plasma cells, and fibroblasts. The erythrocyte sedimentation rate was $70 \mathrm{~mm}$ in one hour. The diagnosis was in doubt until two weeks later he was noted to have a generalized rash, with involvement of palms and soles, and general adenopathy. Serological tests were positive. Routine treatment with penicillin resulted in resolution of his jaundice and reversal of these reactions. No other cause for the jaundice could be suggested. Case 2 was of a 35-year-old bisexual male who had been treated for early syphilis in the primary stage at another clinic the previous year and had developed penicillin hypersensitivity. He attended a medical outpatients department with a tender swelling below his left tibial tuberosity. An $x$-ray showed periostitis. He was referred to the special clinic, where serological tests were found to be positive. The patient was admitted for treatment with a 14-day course of cephaloridine in view of the penicillin allergy, and the symptoms improved. $X$-ray examination three months later showed that his periostitis had resolved, and after one year the reagin titre had fallen to 1 in 2. Case 3 was of a widow aged 47 who attended an eye hospital with anterior uveitis, and a generalized rash was noted. As a result she was referred to the skin department. Serological tests for syphilis were found to be positive, and so she was sent on to the special clinic, where the additional history of two months' arthralgia was noted and papilloedema observed. A course of penicillin was given. Eight weeks later the uveitis had resolved, and the reagin titre had been reduced to 1 in 2 . The fourth case was of a married man aged 39 who complained of deafness and was seen in an E.N.T. department. He then attended the special clinic because he was worried about a recent sex risk. He also complained of arthralgia of six weeks' duration. The E.S.R. was $42 \mathrm{~mm}$ in one hour and the serological tests were positive. There was now a perceptive deafness, more marked on the right side, and papilloedema and a generalized rash. Treponema pallidum was found by dark-ground examination from a split papule at the angle of the mouth. Examination of his spinal fluid showed 173 